Изв. АН Эстонии. Геол., $1993,42,1,15-22$

УДК $561.255: 551.732 / 733.1(474.2)$

Нина ВОЛКОВА *

\title{
АКРИТАРХИ ПОГРАНИЧНЫХ ОТЛОЖЕНИИ КЕМБРИЯ И ОРДОВИКА ПРИГЛИНТОВОЙ ПОЛОСЫ ЭСТОНИИ (СКВАЖИНА М-56)
}

В настоящее время в пограничных отложениях кембрия и ордовика приглинтовой полосы Эстонии установлено три комплекса акритарх, один верхнекембрийский и два нижнетремадокских (Волкова, 1989a, 1990). Верхнекембрийский описан из отложений конодонтовых зон Proconodontus и Cordylodus andresi, что примерно соответствует верхней части трилобитовой надзоны Peltura и низам зоны Acerocare. Этот комплекс, названный как ВК 4Б с Dasydiacrodium palmatilobum, Izhoria angulata, Ooidium rossicum, известен также из ладожской свиты Ленинградской области и из средней части бугинской свиты Московской синеклизы. Первый нижнетремадокский комплекс, названный как комплекс с Acanthodiacrodium angustum, Dasydiacrodium ornatum, Arbusculidium striatulum, происходит из нижней части каллавереской свиты (зона Cordylodus proavus). Второй нижнетремадокский, обозначенный как комплекс с Vulcanisphaera britannica, V. imparila, Baltisphaeridium setaceum, установлен в верхней части этой свиты (зоны Cordylodus lindstromi-C. angulatus/C. rotundatus). Границы нижнетремадокских комплексов пока не ясны, акритархи зоны Cordylodus intermedius не известны (Волкова, 1989а, б).

Сведения об акритархах верхнего тремадока в Эстонии отсутствуют. Для более восточных районов на Русской плите они ограничены только кратким сообщением К. Е. Аристовой (1980). Этим автором в отложениях верхнего тремадока, вскрытых скважиной в Костромской области, найдено несколько видов диакродиевых, а также родов Cymatiogalea и Vulcanisphaera, характерных для верхнего тремадока Польши (Gorka, 1969).

В настоящей статье описаны комплексы акритарх пограничных отложений кембрия и ордовика, вскрытых скважиной M-56 в приглинтовой полосе Эстонии (рисунок). Изученная часть разреза в интервале $132,0-$ 148,1 м представлена чередованием аргиллитов и глин с алевролитами и песчаниками. Возраст отложений изученного интервала при первичном описании керна определен от тискреской свиты нижнего кембрия до варангуской свиты одноименного горизонта (рисунок).

Для изучения акритарх было получено от эстонского геолога Р. Раудсепа 23 образца из интервала $132,0-148,1$ м, за что автор ему искренне признательна. Из них два образца с глубины 147,7 и 148,1 м были пустыми. Большое количество акритарх удовлетворительной или хорошей сохранности было найдено в образцах из интервалов $138,6-147,4$ и

* Геологический институт Российской Академии наук. Россия. 109017 Москва, Пыжевский переулок 7. 
132,0 - 133,9 м. Отложения в интервале 134,2 - 136,5 м насыщены акритархами слабо, сохранность их здесь плохая, реже удовлетворительная. Кроме того, в палинологических препаратах из этого интервала содержалось огромное количество органического аморфного дебриса, который сильно затрудняет поиски и определение акритарх. Аморфный дебрис содержался также в палинологических препаратах и из других интервалов, но в значительно меньшем количестве. Помимо акритарх, в интервале 136,5-145,8 м встречались обломки брахиопод, в интервале 132,0 - 133,9 м - обломки хитинозой. В изученном разрезе выделено три комплекса акритарх. Список всех встреченных таксонов и их распределение по образцам приведены в таблице.

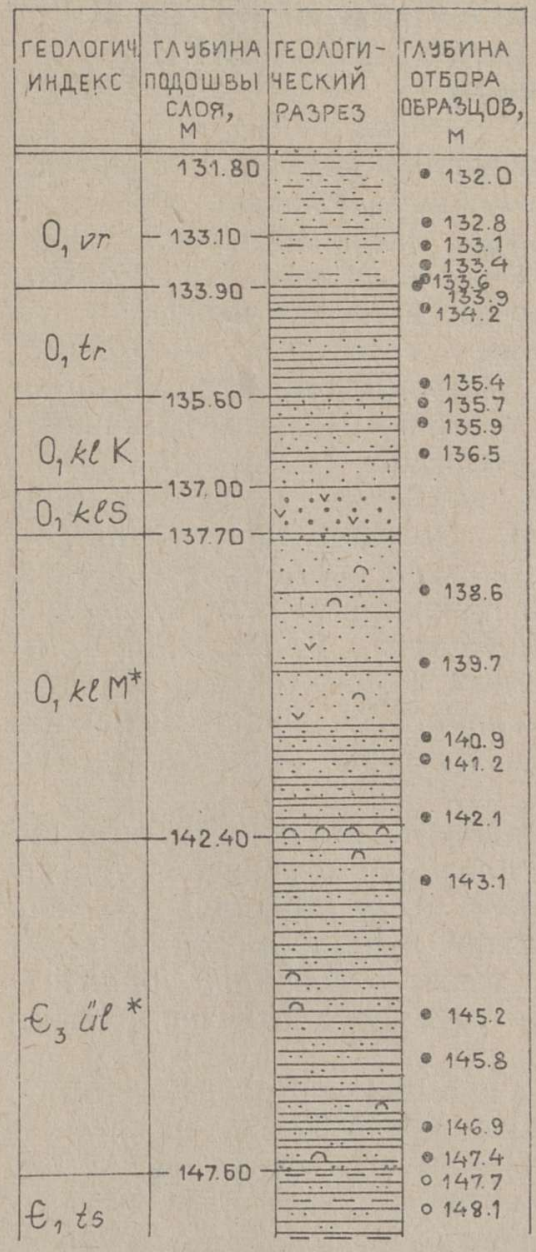

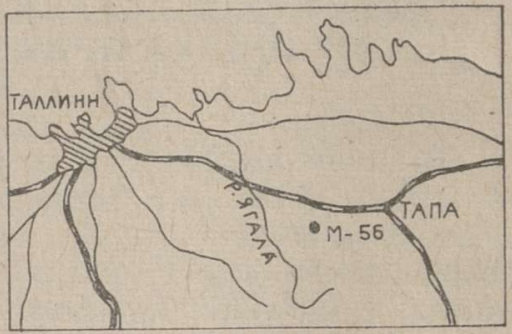

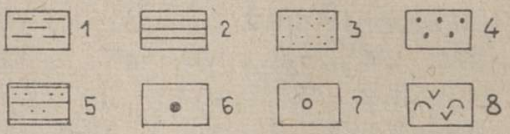

Разрез и местонахождение скважины M-56 по Р. Раудсепу. 1 - глина, 2 аргиллит, 3 - песчаник мелкозернистый, 4 - песчаник среднезернистый, 5-алевролит, 6 - пробы, содержащие акритархи, 7 - пробы пустые, 8 - створки беззамковых брахиопод и их детрит. Стратиграфические индексы: O,vr варангуская свита; $\mathrm{O}_{1} \mathrm{tr}$ - тюрисалуская свита; $\mathrm{O}_{1} \mathrm{klK}$ - кателаская пачка каллавереской свиты; $\mathrm{O}_{1} \mathrm{klS}$ - суурйыгиская пачка каллавереской свиты; O,klM маардуская пачка каллавереской свиты; $\hat{\epsilon}_{3}$ ül - юлгазеская свита; $\hat{E}_{1}$ ts - тискреская свита.

* Эти стратоны по современным представлениям относятся к тситреской свите верхнего кембрия.

Lithostratigraphic section of the Cambrian-Ordovician boundary beds and the location of boring core M-56. Lithostratigraphic subdivision is given after R. Raudsep (Geological Survey of Estonia, Tallinn). Indexes: $\mathrm{O}_{1} \mathrm{vr}-$ Varangu $\mathrm{Fm} . ; \mathrm{O}_{1} \mathrm{tr}-\mathrm{Türisalu}$ Fm.; $\mathrm{O}_{1} \mathrm{klK}$ - Katela $M$. of the Kallavere Fm.; $\mathrm{O}_{1} \mathrm{klS}$ - Suurjōgi $M$. of the Kallavere Fm.; $\mathrm{O}_{1} \mathrm{klM}$ - Maardu M. of the Kallavere Fm.; $\epsilon_{3}$ ül - Ulgase Fm.; $\epsilon_{1}$ ts - Tiskre Fm. Units marked with an asterisk have recently been assigned to the Upper Cambrian Tsitre Formation.

1 - clay, 2 - argillite, 3 - fine sandstone, 4 - medium sandsione, 5 - siltstone, 6 - samples yielding acritarchs, 7 - barren samples, 8 - valves and debris of inarticulate brachiopods. 
Первый комплекс установлен в интервале $138,6-147,4$ м. Из этой части разреза изучены 10 образцов. В комплексе отмечены 56 таксонов. Доминирующее положение занимают диакродиевые $(10,0-43,0 \%)$, а также представители родов Cymatiogalea и Stelliferidium $(32,0-64,0 \%)$, что характерно для холодноводной Средиземноморской провинции (Vavrdova, 1974; Wolf, 1980; Welsch, 1986). Роды Baltisphaeridium и Polygonium играют менее заметную роль, количество их колеблется от 2,5 до $31,5 \%$. Диагностические виды комплекса, позволяющие судить о его возрасте, встречаются в незначительном количестве, часто единичными экземплярами. $\mathrm{K}$ ним относится ряд видов, появляющихся со второй половины зоны Parabolina spinulosa (Acanthodiacrodium timofeevii Golub et Volk., Baltisphaeridium capillatum (Naum.) N. Umn., Ladogella rotundiformis Golub et Volk., Lusatia dendroidea Burmann), но особенно типичны виды, свойственные комплексу ВК 4Б, который происходит из верхней части надзоны Peltura (Волкова, 1990): Acanthodiacrodium polymorphum Tim., Arbusculidium destombesii Deunff, Dasydiacrodium palmatilobum Tim., Elenia armillata (Vand.) Volk., Ooidium rossicum Tim., Schizodiacrodium digermulense (Welsch) (=S. armatum Volk.), S. brevicrinitum Golub et Volk., S. fibrosum Golub et Volk., Stellechinatum uncinatum (Downie) Martin, Vogtlandia cervinacornua (Welsch) ( $=V$. notabilis Volk.). Присутствие перечисленных видов дает полное основание считать изученный комплекс идентичным комплексу BK 4Б с Dasydiacrodium palmatilobum, Izhoria angulata, Ooidium rossicum и отнести вмещающие отложения в интервале $138,6-147,4$ м к верхней части надзоны Peltura, хотя один из номинальных видов (Izhoria angulata) и не обнаружен.

Комплекс ВК 4Б очень своеобразен, он отличается пірисутствием большого количества местных видов. Его состав мало похож на состав микрофлоры A5, известной из надзоны Peltura на Восточном Ньюфаундленде (Martin, Dean, 1981, 1988). Комплекс с Балтийско-Ладожской приглинтовой полосы впервые был найден в ладожской свите Ленинградской области (Волкова, Голуб, 1985), позднее - в средней части бугинской свиты Московской синеклизы и обозначен как ВК 4Б (Волкова, 1990).

Несколько характерных местных элементов этого комплекса были встречены в верхней части группы Дигермул на севере Норвегии, в микрофлоре AVa (Welsch, 1986). Наиболее диагностическое значение имеют находки Ooidium rossicum и Multiplicisphaeridium cervinacornua, на основании присутствия которых автор относит этот комплекс к тремадоку. Оба эти вида были установлены в оболовых слоях Прибалтики, которые М. Велш, опираясь на старые данные Б. В. Тимофеева (1959), считает тремадокскими. В настоящее время нижняя часть оболовых слоев (юлгазеская свита и нижняя часть маардуской пачки каллавереской свиты Эстонии, ладожская свита Ленинградской области), по содержащимся в ніих конодонтам, отнесена к верхнему кембрию (Боровко, Сергеева, 1985). Указанные виды и были обнаружены в ладожской свите и нижней части маардуской пачки. По наблюдениям автора этой статьи (Волкова, 1989a, 1990), оба эти вида не переходят в зону Cordylodus proavus. Их распространение ограничено только верхним кембрием (зоны Proconodontus и Cordylodus andresi). Микрофлору AVа следует скорее всего считать верхнекембрийской.

Қомплекс, очень близкий к ВК 4Б, выявлен недавно на юге о-ва Эланд (Швеция). Он выделен из верхней части надзоны Peltura - P. scarabaeoides в разрезе Дегерхамн (Tongiorgi, Ribecai, 1990). В отложениях этой зоны обнаружены два комплекса акритарх: один (DGH 1a) в нижней части зоны, другой (DGH 1b) в ее верхней части. Комплекс DGH 1a (с Arbusculidium rommelaerei и Vulkanisphaera 
africana) содержит космополитные таксоны и соответствует микрофлоре A5 на Восточном Ньюфаундленде, которая происходит из надзоны Peltura и отчасти Acerocare. B комплексе DGH $1 \mathrm{~b}$ наряду с космополитными таксонами предыдущего комплекса присутствуют местные виды, свойственные комплексу ВК 4Б: Acanthodiacrodium timofeevii, Calyxiella izhoriensis Golub et Volk., Cristallinium pilosum Golub et Volk., Elenia armillata, Ladogella rotundiformis, Schizodiacrodium fibrosum. Эти виды, названные «балтийским» элементом, известны пока только на Русской плите. Сходство комплексов BK 4Б и DGH 1b подтверждает достоверность отнесения комплекса BK 45 к верхней части надзоны Peltura, ранее сделанного только предположительно (Волкова, 1990). Возможно, его нижний возрастной предел не древнее подошвы зоны Peltura scarabaeoides. Bерхний возрастной предел этого комплекса расположен в нижней части зоны Acerocare, ибо идентичный комплекс найден в конодонтовых зонах Protoconodontus и Cordylodus andresi в ряде разрезов приглинтовой полосы Эстонии (Волкова, 1989a). Определить всему возрастному интервалу (верхняя часть надзоны Peltura - низы зоны Acerocare) или какой-либо его части соответствует комплекс ВК 4Б в данном разрезе не представляется возможным.

Второй комплекс выделен в интервале 134,2 - 136,5 м на материале пяти образцов. Во всех образцах наблюдалось обилие органического аморфного дебриса, которым сильно загрязнена поверхноеть акритарх. Содержание акритарх в этих образцах невелико. В трех нижних образцах было подсчитано от 150 до 300 экземпляров, в двух верхних были найдены только единичные экземпляры. Состав комплекса крайне беден, определены всего 10 таксонов, из них до вида только четыре. В комплексе доминируют формы без орнаментации или слабо орнаментированные: Leiosphaeridia spp., Baltisphaeridium setaceum (Tim.), «Петли Эйзенака». Присутствуют единичные экземпляры Acanthodiacrodium cf. ubui Martin, Lunulidia cf. Iunula (Eis.) Eis., Schizodiacrodium digermulense (Welsch) и др. Бедность видового состава, господство сфероморфных и слабо орнаментированных форм, а также обилие органического дебриса могут свидетельствовать о мелководной прибрежной обстановке осадконакопления (Richardson, Rasul, 1990). Определить возраст комплекса трудно из-за почти полного отсутствия характерных видов. Единственным диагностическим видом этого комплекса является B. sełaceum, который известен из верхней части (интервал зон Cordylodus lindstromi-C. angulatus/C. rotundatus) каллавереской свиты (Волкова, 1989б). Он является одним из типичных видов. комплекса акритарх этого уровня (комплекс с Vulcanisphaera britannica, V. imparila, B. setaceum). Кроме того, на этом же уровне появляется Acanthodiacrodium ubui, единичные экземпляры которого плохой сохранности присутствуют в данном комплексе. На этом основании қомплекс можно отнести к нижнему тремадоку и считать его свойственным мелководной прибрежной обстановке этого времени.

Третий комплекс наблюдался в интервале $132,0-133,9$ м на матернале шести образцов (см. фототабл. I-IV). Акритархи здесь хорошей сохранности, обильны (в одном препарате содержалось 500 и более экземпляров) и достаточно разнообразны. В комплексе определены 32 таксона, из которых господствующее положение $(18,5-89,0 \%)$ занимает Stelliferidium furcatum (Deunff) Deunff, Gorka et Rauscher. Этот вид известен из тремадока Сахары (Deunff, 1961, 1964; Deunff и др., 1974) и из верхнего тремадока о-ва Эланд, Швеция (Bagnoli и др., 1988). Наиболее важными видами комплекса, появление которых происходит на уровне верхнего тремадока, являются следующие: Aryballomorpha grootaertii (Martin) emend. Martin et Yin, Athabascaella penica Martin 
et Yin, A. playfordii Martin, A. rossii Martin, Dasydiacrodium tremadocum (Gorka) emend. Tongiorgi, Lua?

Роды Aryballomorpha, Athabascaella и Lua известны из датированных фауной отложений верхнего тремадока на северо-востоке Китая (Martin, Yin, 1988) и в провинции Альберта в Kанаде (Martin, 1984). Стратиграфический интервал родов Aryballomorpha и Lua ограничен верхним тремадоком, род Athabascaella переходит в арениг. Все три рода были недавно также открыты в отложениях, отнесенных к тремадоку в одной из скважин на западе Tехаса, CША (Barker, Miller, 1989). Указанные районы относятся к низкоширотной тепловодной провинции. Во всех работах специально подчеркивается, что акритархи подгруппы диакродиевых в этих районах отсутствуют.

Dasydiacrodium tremadocum и близкие к этому виду формы диакродиевых (Priscotheca raia Deunff, P. prismatica Deunff) распространены в верхнем тремадоке высокоширотной холодноводной Средиземноморской провинции. Они известны из верхнего тремадока Северной Африки (Jardine н др., 1974; Elaouad-Debbaj, 1988), верхнего тремадока (зона Schumardia) Англии (Rasul, 1979) и верхнего тремадока Польши (Gorka, 1969). Присутствие вышеперечисленных видов позволяет считать третий комплекс верхнетремадокским. Этот комплекс носит смешанный характер, в нем присутствуют как тепловодные, так и холодноводные таксоны. Аналогичная верхнетремадокская смешанная ассоциация с Aryballomorpha grootaertii, Athabascaella playfordii, Dasydiacrodium tremadocum найдена на севере о-ва Эланд в Швеции (Bagnoli и др., 1988). Совместное присутствие указанных таксонов в этих регионах вероятно связано с их расположением в то время в умеренных широтах. Присутствие же тепловодных элементов можно объяснить общим потеплением климата в верхнетремадокское время и наступившей трансгрессией. В пользу второго предположения может свидетельствовать тот факт, что в самом нижнем образце, где найден третий комплекс $(133,9$ м), относящемся к началу трансгрессии, тепловодные формы отсутствуют. Ассоциацию акритарх этого образца вполне можно отнести и к холодноводной Средиземноморской провинции.

\section{Выводы}

1. Возраст отложений в изученном разрезе по акритархам определен в пределах верхи верхнего кембрия (верхняя часть надзоны Peltura) верхний тремадок.

2. Уточнен возраст верхнекембрийского комплекса ВК 4Б, нижний возрастной предел которого не древнее подошвы зоны Peltura scarabaeoides.

3. В разрезе-наблюдается перерыв, отвечающий примерно верхам зоны Acerocare - низам зоны Dictyonema flabelliforme. Перерыв приблизительно такого же уровня существует в разрезе Дегерхамн на юге о-ва Эланд, где он связывается с әвстатическим понижением уровня моря.

4. Комплекс верхнего тремадока содержит таксоны, свойственные и холодноводной, и тепловодной провинциям. Это может быть связано как со среднеширотным положением Эстонии, так и с наступившим в это время потеплением климата. 
1-3. Aryballomorpha grootaertii (Martin) emend. Martin et Yin; 1 - преп. ГИН 3937/06400-3; 2 - тот же экземпляр с противоположной стороны; 3 - преп. ГИН 3937/06400-1; обр. 542, гл. 132,8 м.

4. Dictyotidium operculatum Siverz. et Volk; преп. ГИН 3937/06400-2; обр. 542, гл. 132,8 м.

5. Athabascaella rossii Martin emend. Martin et Yin; преп. ГИН 3937/06401-2; обр. 545, гл. $133,1 \mathrm{~m}$.

6, 7. Lua ? sp.; 6 - преп. ГИН 3937/06400-3; 7 - преп. ГИН 3937/06400-1; обр. 542, гл. 132,8 м.

Все экземпляры проиеходят из отложений верхнего тремадока.

\section{ТАБЛИЦА II}

1, 2. Athabascaella penica Martin et Yin; 1 - преп. ГиН 3937/06399-2; обр. 541, гл. 132,0 м; 2 - преп. ГИН 3937/06400-3; обр. 542, гл. 132,8 м.

3, 6. Athabascaella playfordii Martin emend. Martin et Yin; 3 - преп. ГИН 3937/06399-2; 6 - преп. ГИН 3937/06399-1; обр. 541, гл. 132,0 м.

4. Baltisphaeridium sp. 1; преп. ГИН 3937/06400-3; обр. 542, 132,8 м.

5. «Петли Эйзенака»; преп. ГИН 3937/06400-3; обр. 542, гл. 132,8 м.

Все экземпляры происходят из отложений верхнего тремадока.

\section{ТАБЛИЦА III}

1. Lophodiacrodium sp.; преп. ГИН 3937/06402-3; обр. 546, гл. 133,4 м.

2. Acanthodiacrodium formosum Gorka; преп. ГИН 3937/06400-3; обр. 542, гл. 132,8 м.

3. Actinotodissus sp.; преп. ГИН 3937/06399-1; обр. 541, гл. 132,0 м.

4. Dasydiacrodium tumidum (Deunff) Tongiorgi; преп. ГИН 3937/06404; обр. 548, гл. 133,9 м.

5. Actinotodissus sicaformis (Molyneux) Siverz. et Volk.; преп. ГИН 3937/06401-1; обр. 545, гл. 133,1 м.

6. Micrhystridium sp., преп. ГИН 3937/06399-2; обр. 541, гл. 132,0 м.

7. Acanthodiacrodium angustum (Downie) Combaz; преп. ГИН 3937/06403-1; обр. 547, гл. 133,6 м.

8, 9. Aranidium sp.; преп. ГИН $3937 / 06400-3$; обр. 542 , гл. 132,8 м.

10. Dasydiacrodium tremadocum (Gorka) Tongiorgi; преп. ГИН 3937/06402-3; обр. 546, гл. 133,4 м.

Все экземпляры происходят из отложений среднего-верхнего тремадока.

\section{ТАБЛИЦА IV}

1--3. Cymatiogalea sp.; преп. ГИН 3937/06404-3; обр. 548, гл. 133,9 м; 1, 2- противоположные стороны одного и того же экземпляра.

4, 6-9. Stelliferidium furcatum (Deunff) emend. Deunff Gorka et Rauscher; 4, 9 преп. ГИН 3937/06399-1; обр. 541, гл. 132,0 м; 6-8 - преп. ГИН 3937/06400-3; обр. 542, гл. 132,8 м; 8 - изолированная крышка.

5. Caldariola glabra (Martin) Molyneux; преп. ГИН 3937/06402-3; обр. 546, гл. 133,4 м. 10-12. Cymatiogalea sp.; 10 - преп. ГИН 3937/06400-1, 11 - преп. ГИН 3937/06400-3; обр. 542, гл. 132,8 м; 12 - преп. ГИН 3937/06399-2; обр. 541, гл. 132,0 м. Все экземпляры происходят из отложений верхнего тремадока. Увеличение $\times 1000$.

All figured acritarchs in Pls. I-IV are from the Varangu Formation; specimens are housed at the Geological Institute of the Russian Acad. Sci., Moscow; magnification $\times 1000$. 

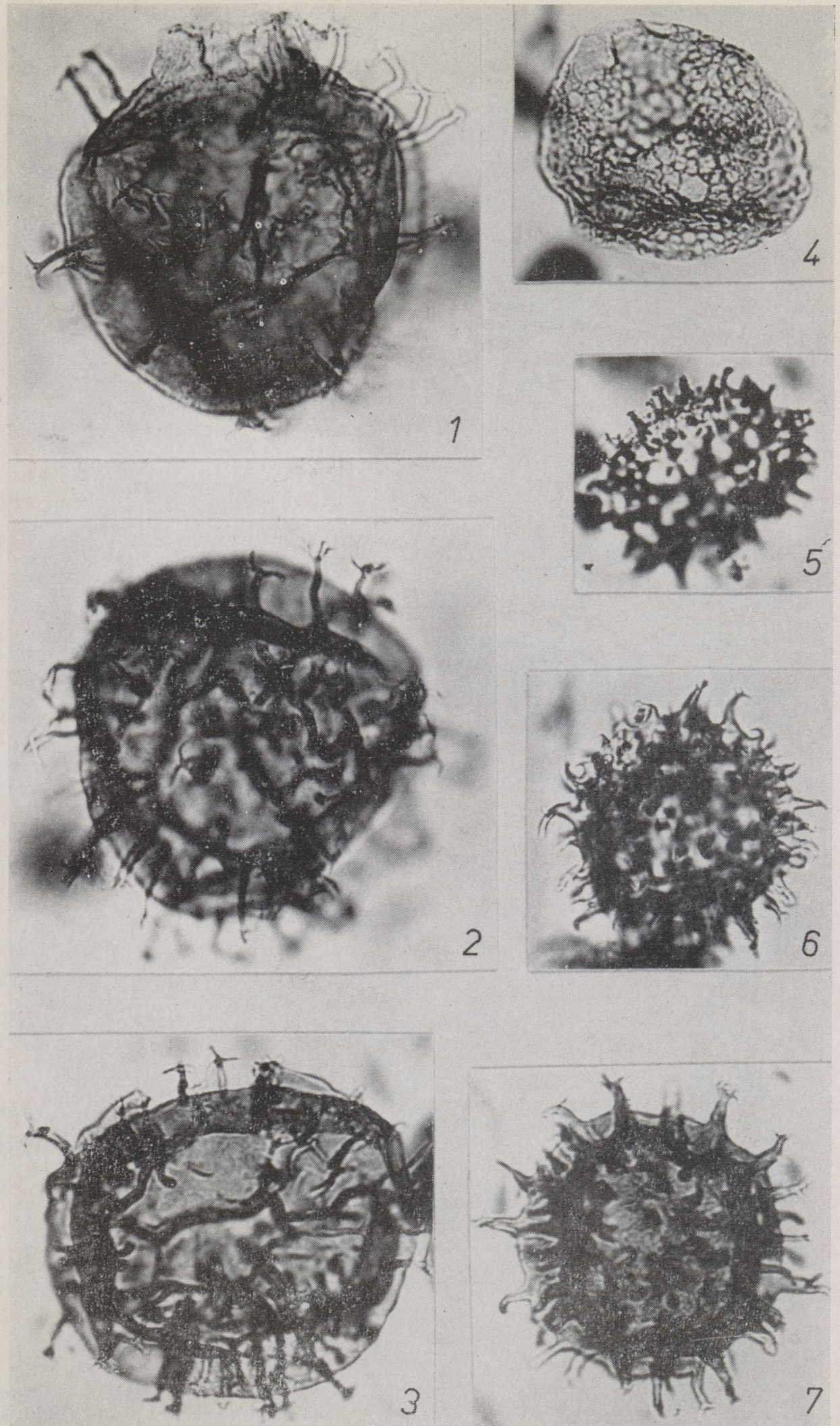

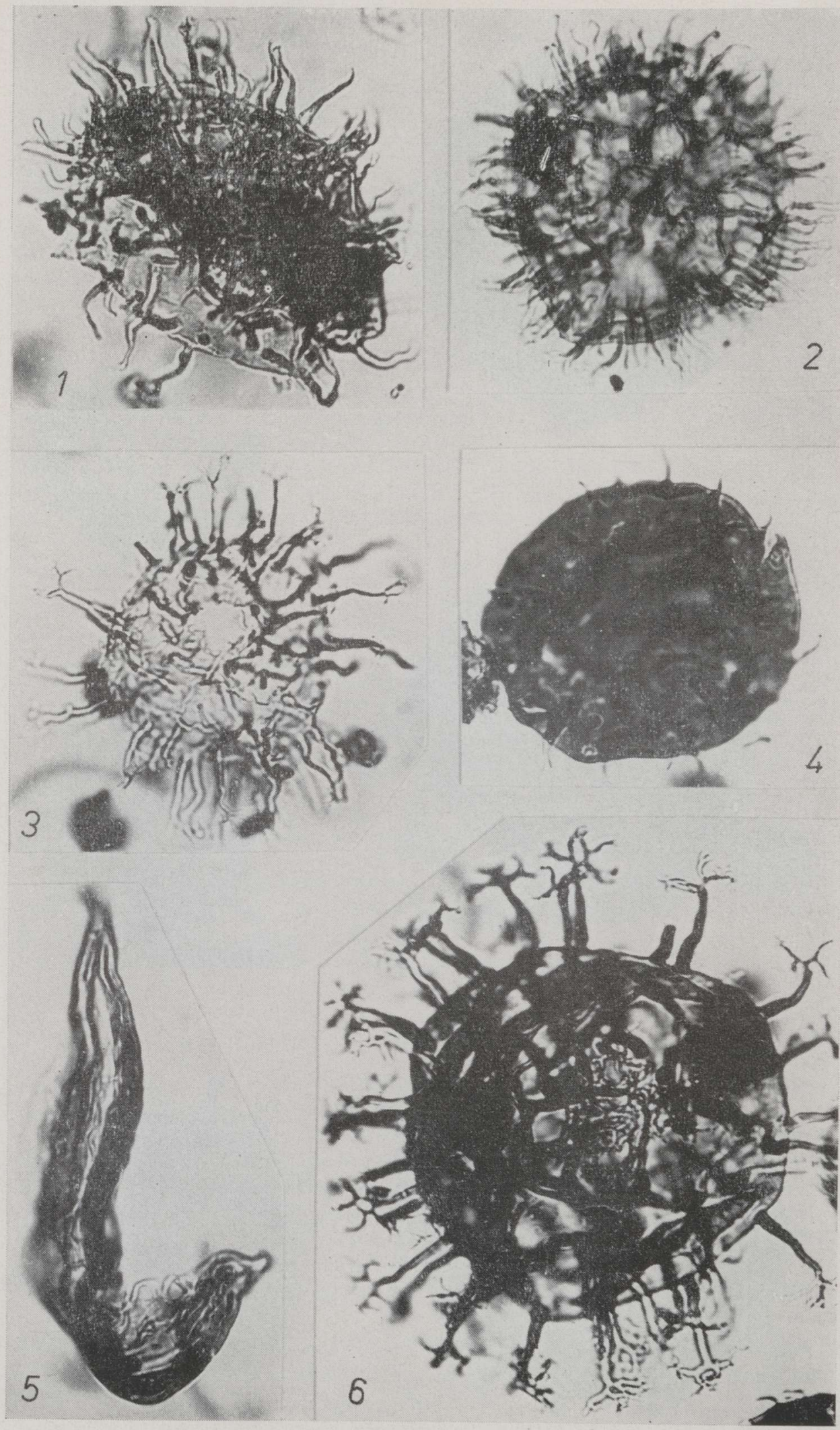

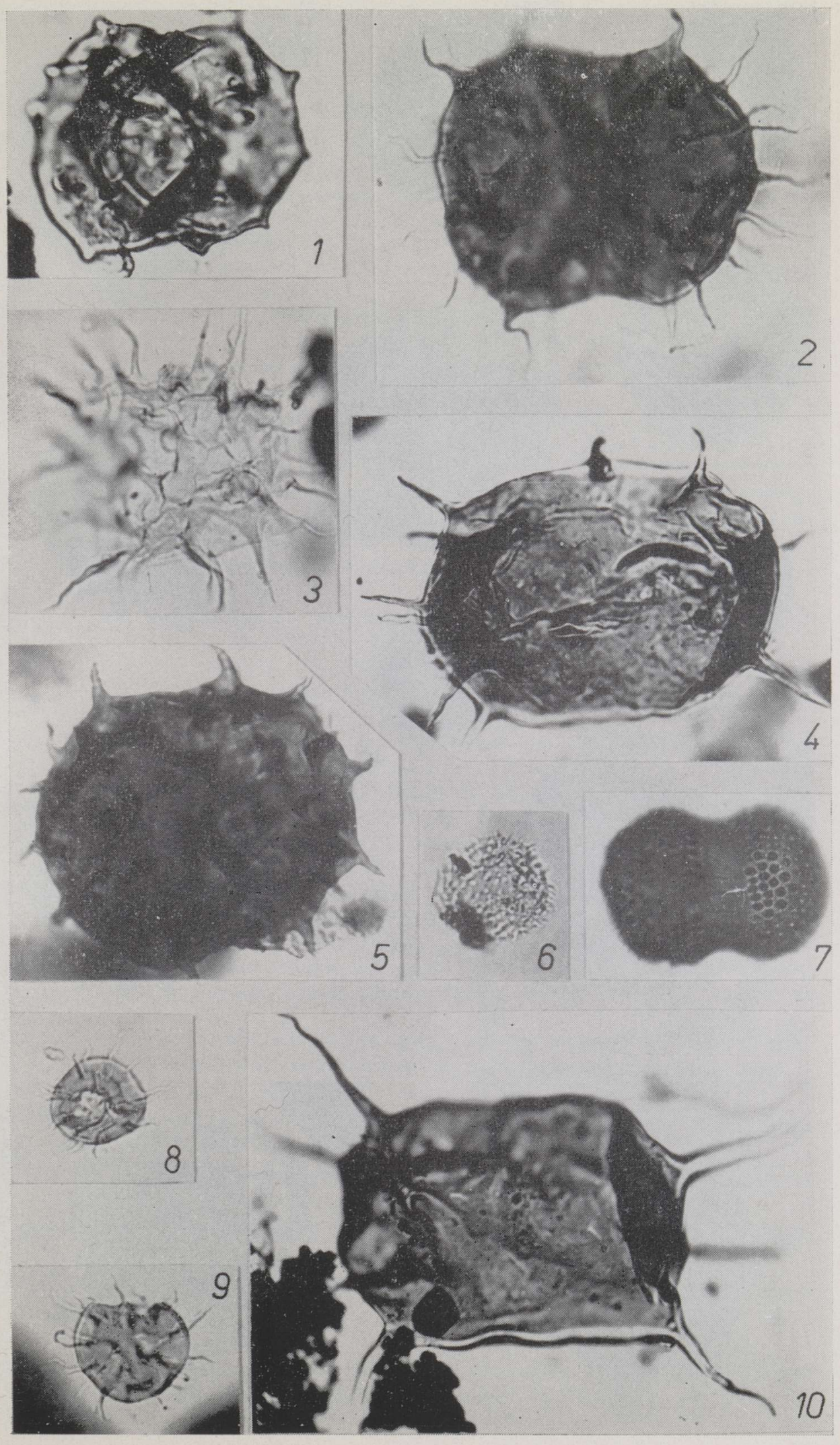

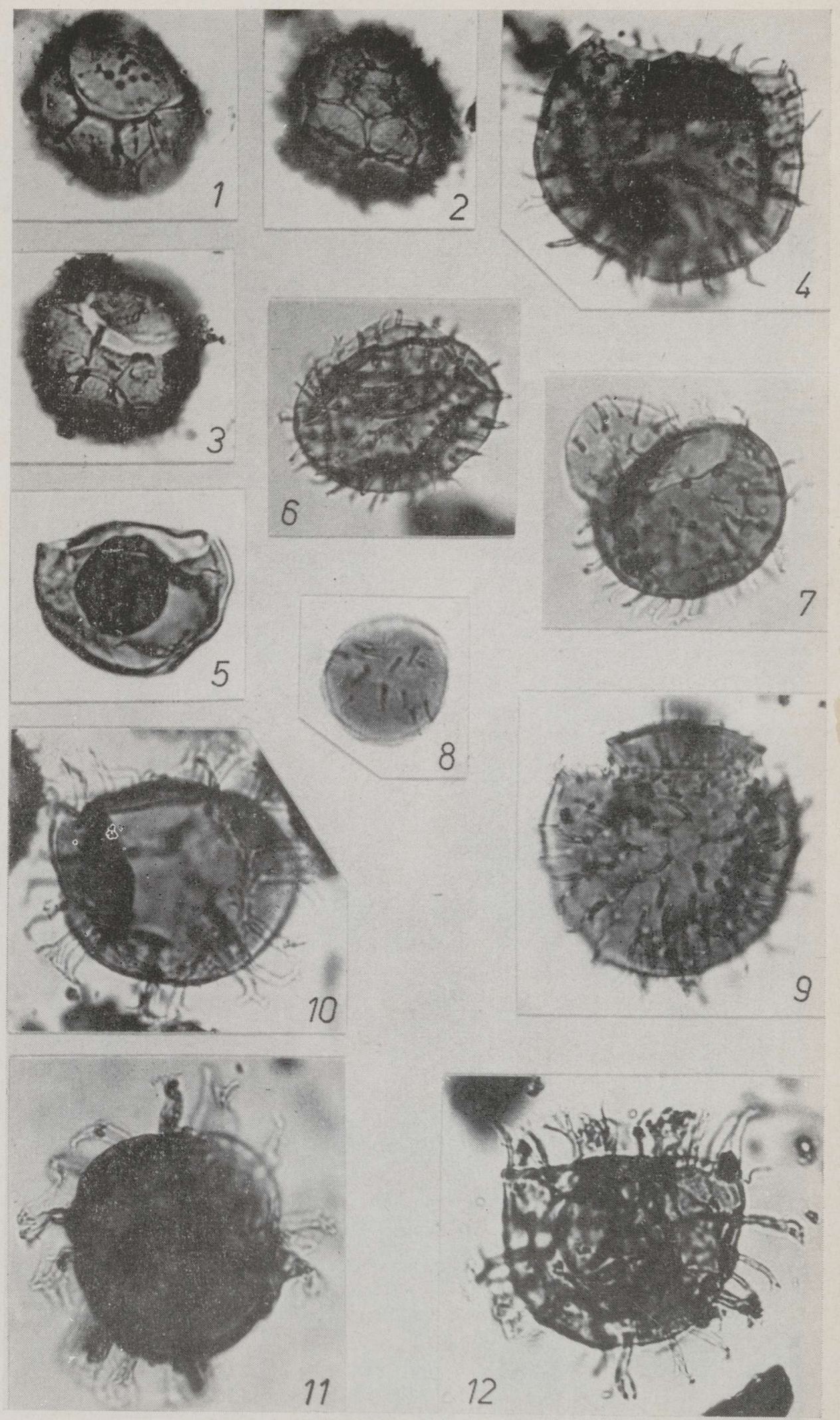
Аристова K. Е. 1980. Акритархи пограничных слоев тремадокского и аренигского ярусов Московской синеклизы. - Тр. Всес. н.-и. геол.-развед. нефт. ин-та, $217,10-18$.

Боровко Н., Сергеева С. 1985. Конодонты верхнекембрийских отложений БалтийскоЛадожского глинта. - Изв. АН ЭССР. Геол., 34, 4, 125-129.

Волкова Н. А. 1989а. Акритархи пограничных отложений кембрия и ордовика севера Эстонии. - Изв. АН СССР. Сер. геол., 7, 59-67.

Волкова Н. А. 1989б. Акритархи верхней части пакерортского горизонта севера Эстонии и Ленинградской области. - В кн.: Палеофлористика и стратиграфия фанерозоя. Изд-во ГИН, Москва, 4-16.

Волкова Н. А. 1990. Акритархи среднего и верхнего кембрия Восточно-Европейской платформы. Наука, Москва.

Волкова Н. А., Голуб И. Н. 1985. Новые акритархи верхнего кембрия Ленинградской области (ладожская свита). - Палеонтол. ж., 4, 90-98.

Тимофеев Б. В. 1959. Древнейшая флора Прибалтики и ее стратиграфическое значение. Гостоптехиздат, Ленинград.

Bagnoli, G., Stouge, S., Tongiorgi, M. 1988. Acritarchs and conodonts from the CambroOrdovician Furuhäll (Köpingsklint) section (Öland, Sweden). - Riv. Ital. Paleontol. e Stratigr., 94, 2, 163-248.

Barker, G. W., Miller, M. A. 1989. Tremadocian (Lower Ordovician) acritarchs from the subsurface of West Texas. - В кн.: 22nd Ann. Meet. Amer. Ass. Stratigr. Palynologists. Tulsa, Okla, Oct. 18-21, 1989. Program and Abstr. Dallas (Tex.).

Deunff, J. 1961. Un microplancton à Hystrichosphères dans le Trémadoc du Sahara. Rev. micropaléontol., 4, 1, 37-52.

Deunff, J. 1964. Systématique du microplancton fossile à acritarches. Revision de deux genres de l'Ordovicien inférieur. - Rev. micropaléontol., 7, 2, 119-124.

Deunff, J., Gorka, H., Rauscher, R. 1974. Observations nouvelles et précisions sur les acritarches à large ouverture polaire du Paléozoique inférieur. - Geobios., 7, 1, $5-18$.

Elaouad-Debbaj, Z. 1988. Acritarches et chitinozoaires du Trémadoc de l'Anti-Atlas central (Maroc). - Rev. micropaléontol., 31, 2, 85-128.

Gorka, H. 1969. Microorganismes de l'Ordovicien de Pologne. - Palaeontol. polon, 22.

Jardine, S., Combaz, A., Magloire, L., Peniguel, G., Vachey, G. 1974. Distribution stratigraphique des acritarches dans le Paléozoique du Sahara Algérien. - Rev. Palaeobot. and Palynol., 18, 1/2, 99-129.

Martin, F. 1984. New Ordovician (Tremadoc) acritarch taxa from the middle member of the Survey Peak formation at Wilcox Pass, southern Canadian Rocky Mountains, Alberta. - Geol. Surv. Canada, Curr. Res. A, Pap. 84-1A, 441-448.

Martin, F., Dean, W. T. 1981. Middle and upper Cambrian and lower Ordovician acritarchs from Random Island, eastern Newfoundland. - Bull. Geol. Surv. Canada, 343.

Martin, F., Dean, W. T. 1988. Middle and upper Cambrian acritarch and trilobite zonation at Manuels River and Random Island, eastern Newfoundland. - Bull. Geol. Surv. Canada, 381.

Martin, F., Yin, L. 1988. Early Ordovician acritarchs from southern Jilin province, northeast China. - Palaeontology, 31, 1, 109-127.

Rasul, S. M. 1979. Acritarch zonation of the Tremadoc series of the Shineton shales, Wrekin, Shropshire, England. - Palynology, 3, 53-72.

Richardson, J. B., Rasul, S. M. 1990. Palynofacies in a late Silurian regressive sequence in the Welsh Borderland and Wales. - J. Geol. Soc. London, 147, 675-686.

Tongiorgi, M., Ribecai, C. 1990. Late Cambrian and Tremadocian phytoplankton (acritarchs) communities from Oland (Sweden). - Bull. Soc. Paleontol. Ital., 29, 1, $77-88$.

Vavrdova, M. 1974. Geographical differentiation of Ordovician acritarch assemblages in Europe. - Rev. Palaeobot. and Palynol., 18, 1-2, 171-175. 
Welsch, M. 1986. Die Acritarchen der höheren Digermul-Gruppe, Mittelkambrium bis Tremadoc, Ost-Finnmark, Nord-Norwegen. - Palaeontographica, Abt. B, 201, $1-4$.

Wolf, R. 1980. The lower and upper boundary of the Ordovician system of some selected regions (Celtiberia, Eastern Sierra Morena) in Spain. Part 1: The lower Ordovician sequence of Celtiberia. - Neues Jahrb. Geol. und Paläontol. Abh., 160, 1, $118-137$.

Представил Э. Пиррус

Поступила в редакцию $12 / V I 1992$

Niina, VOLKOVA

\section{KAMBRIUMI JA ORDOVIITSIUMI PIIRIKIHTIDE AKRITARHID EESTI KLINDIVOOONDI PUURSUDAMIKUS M-56}

Puursüdamiku M-56 kambriumi ja ordoviitsiumi piirikihtidest (intervall 132,0$148,1 \mathrm{~m}$ ) on määratud kolm akritarhide kompleksi. Alumises akritarhide kompleksis leidub hiliskambriumi vorme ja seda sisaidavaid kihte võib korreleerida Peltura scarabaeoides Acerocare alumise osa trilobiiditsoonidega. Keskmine ja ülemine kompleks sisaldavad lisaks ka alamordoviitsiumi like ning iseloomustavad vastavalt Alam- ja Olem-Tremadoci setendeid. Cordyiodus proavus'e tsoonile vastab aga uuritud läbilooikes stratigraafiline lünk.

\section{Nina VOLKOVA}

\section{ACRITARCHS FROM THE CAMBRIAN-ORDOVICIAN BOUNDARY BEDS (BORING CORE M-56) OF THE ESTONIAN NEAR-CLINT AREA}

The Cambrian-Ordovician boundary interval in the boring core embraces deposits from the Lower Cambrian Tiskre to the Lower Ordovician Varangu formations and is mostly represented by areanaceous and argillaceous rocks (Figure).

Twenty three samples from the interval $132.0-148.1 \mathrm{~m}$ were studied and three acritarch assemblages were established (Table). The lowermost and uppermost assemblages are diverse and consist of well-preserved specimens, whereas the middle one is poor in species and is represented by rare ill-preserved specimens.

The lowermost assemblage, yielding beside numerous local species Dasydiacrodium palmatilobum, Ooidium rossicum, Vogtlandia cervinacornua, etc. can be assigned to the Peltura scarabaeoides Zone and probably also to the lower half of the Acerocare Zone.

The second and third assemblages, comprising the Ordovician species, correspond to the early and late Tremadoc, respectively. The acritarch assemblage, typical of the Cordylodus proavus Zone, lacks the studied samples indicating a probable hiatus in the stratigraphic succession.

The late Tremadoc assemblage shows the taxa uncommon both in high-latitude cold-water and low-latitude warm-water provinces. This may be due to the position of Estonia in middle latitudes, as well as to climatic warming. 